\title{
Capacitive Properties of Mesoporous Mn-Co Oxide Derived from a Mixed Oxalate
}

\author{
Yong Yan, Bingcai Wu, Cuihong Zheng, Daolai Fang*
}

School of Materials Science and Engineering and Anhui Key Laboratory of Metal Materials and Processing, Anhui University of Technology, Ma'anshan, China.

Email: *fangdl@ahut.edu.cn

Received March $7^{\text {th }}, 2012$; revised April 13 ${ }^{\text {th }}, 2012$; accepted May $17^{\text {th }}, 2012$

\begin{abstract}
A mesoporous Mn-Co oxide for supercapacitors was derived from a mixed oxalate $\mathrm{Mn}_{0.8} \mathrm{Co}_{0.2} \mathrm{C}_{2} \mathrm{O}_{4} \cdot \mathrm{nH}_{2} \mathrm{O}$, which was synthesized by a solid-state coordination reaction at room temperature. The synthesized mixed $\mathrm{Mn}$-Co oxalate was decomposed in air at $250^{\circ} \mathrm{C}$, resulting in a tetragonal spinel Mn-Co oxide with a primary particle size less than $100 \mathrm{~nm}$. The obtained Mn-Co oxide presents a mesoporous texture with a specific surface area of $120 \mathrm{~m}^{2} \cdot \mathrm{g}^{-1}$. Electrochemical properties of the Mn-Co oxide electrode were investigated by cyclic voltammetry and galvanostatic charge/discharge in $6 \mathrm{~mol} \cdot \mathrm{L}^{-1} \mathrm{KOH}$ electrolyte. The Mn-Co oxide electrode delivered specific capacitances of 383 and $225 \mathrm{~F} \cdot \mathrm{g}^{-1}$ at scan rates of 2 and $50 \mathrm{mV} \cdot \mathrm{s}^{-1}$, respectively. Subjected to 500 cycles at a current density of $1.34 \mathrm{~A} \cdot \mathrm{g}^{-1}$, the symmetrical $\mathrm{Mn}$-Co oxide capacitor showed specific capacitance of $179 \mathrm{~F} \cdot \mathrm{g}^{-1}$, still retaining $\sim 85 \%$ of its initial capacitance. The obtained Mn-Co oxide material showed good capacitive performance, which was promising for supercapacitor applications.
\end{abstract}

Keywords: Supercapacitors; Manganese Oxide; Solid-State Reaction; Cyclic Voltammetry; Capacitive Performance

\section{Introduction}

Electrochemical supercapacitors possess the unique energy-storage performance, such as greater power density and longer cycle life than secondary batteries, as well as higher energy density than conventional capacitors [1], showing great potential to be used in the areas of hybrid power sources, peak power sources, backup power storage, lightweight electronic fuses, starting power of fuel cells $[2,3]$. Generally the supercapacitors can be classified into two categories: electrical-double-layer capacitors (EDLCs), which build up electrical charge at the electrode/electrolyte interface [4,5], and pseudocapacitors, which are based on reversible faradic redox reactions at the interfaces at certain potentials [6-10].

Recently, with the purpose of achieving high energy density supercapacitors, great efforts have been devoted to search for excellent pseudocapacitive materials [1120]. Amorphous hydrated ruthenium oxide has been demonstrated to be an excellent pseudocapacitor material, which exhibits a high conductivity, good electrochemical stability, and a large specific capacitance (SC) of 720 $760 \mathrm{~F} \cdot \mathrm{g}^{-1}[21]$. However, high cost and toxicity of the ruthenium oxide greatly limit its commercial applications. Thus, other less expensive and less toxic transition metal

"Corresponding author. oxides, such as amorphous and crystallized $\mathrm{MnO}_{2}[11-$ 14], nanostructured $\mathrm{NiO}[15,16]$, and mesoporous and nanowire-array $\mathrm{Co}_{3} \mathrm{O}_{4}[17,18]$, have been developed as electrode materials for supercapacitors. The electrode materials of the cheaper transition metal oxides exhibit remarkable capacitive nature, delivering a considerable SC. However, the resistivity and the equivalent series resistance (ESR) of these cheaper transition metal oxides are very large, which greatly limits their capacity and power density available.

On the other hand, it is reported that mixed oxide composites exhibit superior capacitive performance to single transition metal oxides. It has been demonstrated that the incorporation of $\mathrm{Ni}[19], \mathrm{Pb}$ [20], Mo [22], and $\mathrm{V}$ [23] oxides into pristine manganese oxide can enhance specific capacitance and electrical conductivity of pristine manganese oxide. Nevertheless, the effect of $\mathrm{Co}$ oxide addition into pristine manganese oxide has not been extensively studied yet, and the results from different research groups vary significantly [24-26].

In this work, a mesoporous Mn-Co oxide was derived from a mixed $\mathrm{Mn}_{0.8} \mathrm{Co}_{0.2} \mathrm{C}_{2} \mathrm{O}_{4} \cdot \mathrm{nH}_{2} \mathrm{O}$, which was synthesized by a solid-state coordination reaction. Its phase compositions and microstructures were characterized by $\mathrm{X}$-ray diffraction (XRD), scanning electron microscope (SEM) and $\mathrm{N}_{2}$ adsorption-desorption measurements, and 
its electrochemical properties were analyzed by cyclic voltammetry and galvanostatic charge/discharge cycling. Considering the considerable content of cobalt added in the prepared Mn-Co oxides, and a remarkable pseudocapacitive behavior of cobalt oxide in alkaline aqueous electrolyte [17,18], $\mathrm{KOH}$ aqueous electrolyte was used to investigate the electrochemical properties of the Mn-Co oxide. The obtained Mn-Co oxide shows excellent capacitive performance in terms of specific capacitance (SC), power capability and cycling stability, which is promising for supercapacitor applications.

\section{Experimental}

\subsection{Synthesis of the Mn-Co Oxide Powder}

Analytical-grade manganese acetate $\mathrm{Mn}\left(\mathrm{CH}_{3} \mathrm{COO}\right)_{2} \cdot 4 \mathrm{H}_{2} \mathrm{O}$, cobalt acetate $\mathrm{Co}\left(\mathrm{CH}_{3} \mathrm{COO}\right)_{2} \cdot 4 \mathrm{H}_{2} \mathrm{O}$, and oxalic acid $\mathrm{H}_{2}$ $\mathrm{C}_{2} \mathrm{O}_{4} \cdot 2 \mathrm{H}_{2} \mathrm{O}$ were used as starting materials. All the reagents were purchased from Sinopharm Group Chemical Reagent Company in China, and used as received. A proper amount of the starting materials was weighed accurately with a molar ratio of $\mathrm{Mn}\left(\mathrm{CH}_{3} \mathrm{COO}\right)_{2} \cdot 4 \mathrm{H}_{2} \mathrm{O}$ : Co$\left(\mathrm{CH}_{3} \mathrm{COO}\right)_{2} \cdot 4 \mathrm{H}_{2} \mathrm{O}: \mathrm{H}_{2} \mathrm{C}_{2} \mathrm{O}_{4} \cdot 2 \mathrm{H}_{2} \mathrm{O}$ of 0.8:0.2:1.1, then mixed and milled in a mortar to form a powder mixture. Subsequently, the obtained powder mixture was ball milled at room temperature for $5 \mathrm{~h}$ in a polyethylene container using zirconia balls as milling medium. The milled mixture was dried at $80^{\circ} \mathrm{C}$, resulting in a Mn-Co oxalate precursor. Finally, the Mn-Co oxalate precursor was calcined in air at $250^{\circ} \mathrm{C}$ for $10 \mathrm{~h}$ to obtined Mn-Co oxide.

\subsection{Structural Characterization}

A Philips X'pert Pro X-ray diffractometer with $\mathrm{CuK}_{\alpha}$ radiation $(\lambda=1.5406 \AA)$ was used to analyze the phase compositions of the dried milled mixture and the calcined Mn-Co oxide. Diffraction data were collected in the $2 \theta$ range from $15^{\circ}$ to $80^{\circ}$, using the step-scan mode with a scanning speed of $0.02^{\circ}$ step-size and $1 \mathrm{~s}$ per step. The morphology of the obtained Mn-Co oxide was observed by using a JSM 6490 scanning electron microscope (SEM). $\mathrm{N}_{2}$ adsorption-desorption measurements were carried out at a Coulter SA 3100 system at $77.3 \mathrm{~K}$. The surface area was calculated using the Brunauer-Emmett-Teller (BET) equation. Pore size distributions were calculated by the Barrett-Joyner-Halenda (BJH) method. Samples were dried and degassed for $2 \mathrm{~h}$ at $150^{\circ} \mathrm{C}$ to remove any surface organic or moisture contaminants.

\subsection{Electrochemical Characterization}

The electrodes for electrochemical measurements consisted of the prepared Mn-Co oxide, acetylene black (AB) and polytetrafluoroethylene (PTFE), whose weight ratio was 75:20:5. First, the Mn-Co oxide and the acetylene black were fully mixed and ground, then a proper amount of PTFE binder was added into the powder mixture to achieve a homogenous slurry, followed by painting the prepared slurry onto a nickel foam current collector with an area of $1 \mathrm{~cm} \times 1 \mathrm{~cm}$. Finally, the painted current collector was dried for $10 \mathrm{~h}$ at $80^{\circ} \mathrm{C}$, and pressed at a pressure of $10 \mathrm{MPa}$ to form a reliable electrode. Each of the fabricated electrodes contained $\sim 4 \mathrm{mg}$ of the Mn-Co oxide electroactive material.

All the electrochemical measurements concerned were carried out in $6 \mathrm{~mol} \cdot \mathrm{L}^{-1} \mathrm{KOH}$ aqueous electrolyte. Cyclic voltammetric measurements were performed on a CHI604C electrochemical workstation in a three-electrode cell set-up, using a Mn-Co oxide electrode as the working electrode, a platinum foil as the counter electrode, a saturated calomel electrode (SCE) as the reference electrode. Cyclic voltammograms at various scan rates were recorded between -0.4 and $0.4 \mathrm{~V}$ vs. SCE.

For evaluation of galvanostatic charge/discharge performance of the obtained Mn-Co oxide electrodes, a symmetrical capacitor was assembled using a couple of the identical electrodes separated by a porous polypropylene separator. The galvanostatic charge/discharge performance at different current densities was determined by a battery test system of Neware BTS-3008W in a potential range from 0 to $0.8 \mathrm{~V}$.

\section{Results and Discussion}

\subsection{Phase Compositions and Microstructures}

Figure 1(a) gives the XRD pattern of the Mn-Co oxalate synthesized by a solid-state coordination reaction. The XRD pattern of the synthesized Mn-Co oxalate matches that of $\alpha$-form manganese oxalate (JCPDS, No. 25-0544), suggesting that the synthesized oxalate is a binary Mn-Co mixed oxalate [27]. Considering a molar ratio of $\mathrm{Mn}^{2+}$ : $\mathrm{Co}^{2+}$ of $4: 1$ in the mixture of the starting materials used, and almost no loss of metal ions during ball-milling, the obtained Mn-Co oxalate can be expressed as a chemical formula of $\mathrm{Mn}_{0.8} \mathrm{Co}_{0.2} \mathrm{C}_{2} \mathrm{O}_{4} \cdot \mathrm{nH}_{2} \mathrm{O}$. Figure $\mathbf{1}(\mathbf{b})$ shows the

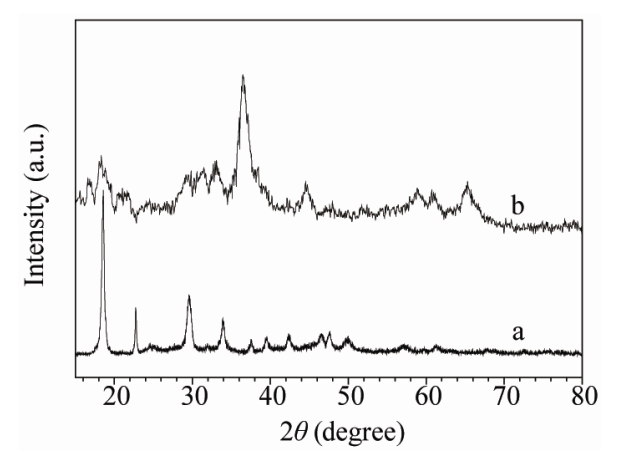

Figure 1. XRD patterns of (a) the Mn-Co oxalate and (b) the obtained Mn-Co oxide. 
XRD pattern of the Mn-Co oxide powder. No characteristic diffraction peaks of the Mn-Co oxalate are observed in the XRD patttern of the calcined Mn-Co oxide in Figure 1(b), indicating that thermal decomposition of the $\mathrm{Mn}-\mathrm{Co}$ oxalate is nearly completed in air at $250^{\circ} \mathrm{C}$ in the duration of $10 \mathrm{~h}$. The low intensity and remarkable broadening of the diffraction peaks disclose that the obtained Mn-Co oxide is poorly crystallized. The discernible peaks around $2 \theta=18.2^{\circ}, 29.3^{\circ}, 31.4^{\circ}, 32.9^{\circ}, 36.5^{\circ}, 44.6^{\circ}, 58.9^{\circ}$, $60.3^{\circ}$ and $65.3^{\circ}$ are well in accordance with those of tetragonal spinel $\mathrm{Mn}_{3} \mathrm{O}_{4}$ (JCPDS, No. 89-4837). Nevertheless, compared with the tetragonal spinel $\mathrm{Mn}_{3} \mathrm{O}_{4}$, the positions of the diffraction peaks for $\mathrm{Mn}-\mathrm{Co}$ oxide shift positively, indicating the smaller lattice parameters of the obtained Mn-Co oxide. It has been demonstrated that the length of the $\mathrm{Co}^{\mathrm{n}+}-\mathrm{O}$ bond is smaller than that of the $\mathrm{Mn}^{\mathrm{n}+}-\mathrm{O}$ bond in the identical sublattice of a spinelstructured mixed oxide [28]. The smaller lattice parameters of the obtained Mn-Co oxide imply that the Co cations are incorporated into the crystal lattice of the tetragonal spinel $\mathrm{Mn}_{3} \mathrm{O}_{4}$, forming a single-phase Mn-Co mixed oxide. Therefore, the chemical formula of the obtained spinel $\mathrm{Mn}-\mathrm{Co}$ oxide can be denoted as $\mathrm{Mn}_{2.4} \mathrm{Co}_{0.6} \mathrm{O}_{4}$. Formation of the spinel Mn-Co oxide at a low calcination temperature of $250^{\circ} \mathrm{C}$ is probably related to the compositional homogeneity of the synthesized Mn-Co mixed oxalate [27].

Figure 2 shows the SEM images of the obtained Mn-Co oxide powder under different magnification. As seen from the lower-magnification SEM image in Figure 2(a),

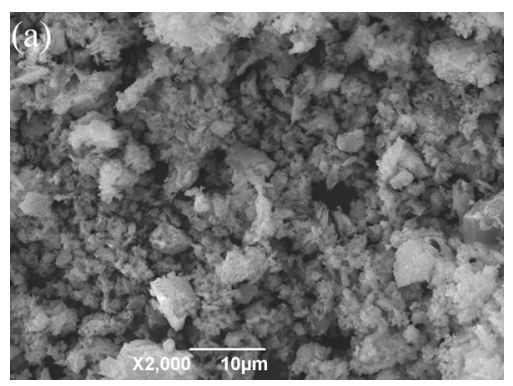

(a)

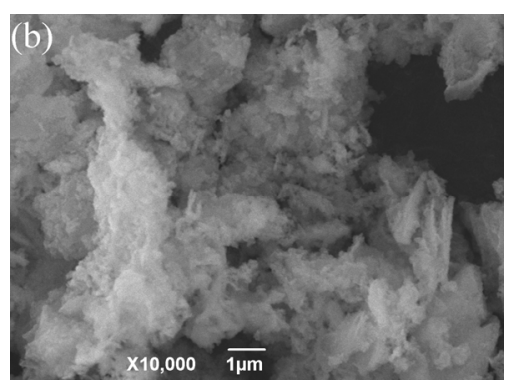

(b)

Figure 2. SEM images of the Mn-Co oxide powder under (a) lower and (b) higher magnification. the obtained Mn-Co oxide powder is composed of irregular-shaped agglomerates with a size less than $5 \mu \mathrm{m}$. The higher-magnification SEM image in Figure 2(b) shows that each of the irregular agglomerates observed under lower magnification actually contains a great number of ultrafine primary particles with a particle size less than $100 \mathrm{~nm}$. The ultra-fine particles of the prepared MnCo oxide certainly lead to a larger surface area available for charge storage, which is beneficial to en hancing its supercapacitive performance.

The mesoporosity and textural properties of the asprepared Mn-Co oxide was investigated by $\mathrm{N}_{2}$ adsorption-desorption measurement at liquid $\mathrm{N}_{2}$ temperature. Figure 3 gives the $\mathrm{N}_{2}$ adsorption-desorption isotherm and $\mathrm{BJH}$ pore-size distribution of the Mn-Co oxide. It can be seen that the isotherm presents a typical type IV sorption behavior, indicating a mesoporous structure of the obtained Mn-Co oxide according to the classification of IUPAC [29]. Furthermore, there is an abrupt increase in adsorption volume of adsorbed $\mathrm{N}_{2}$ at a certain $P / P_{0}$ value of 0.52 . The sharp increase is generally attributed to capillary condensation, and the $P / P_{0}$ position of the inflection is associated with the pore size [30]. The BJH pore-size distribution, as given in the inset of Figure 3, reveals that the pore size distribution for the Mn-Co oxide is narrow and situated in the mesoporous region (2 $50 \mathrm{~nm}$ ). Also the textural properties of the Mn-Co oxide are given in Table 1. This demonstrates that the synthesis route of the solid-state coordination reaction we adopted allows the obtained Mn-Co oxide with a mesoporous structure and a considerable BET surface area, which are the desired textural properties for high-performance supercapacitor materials.

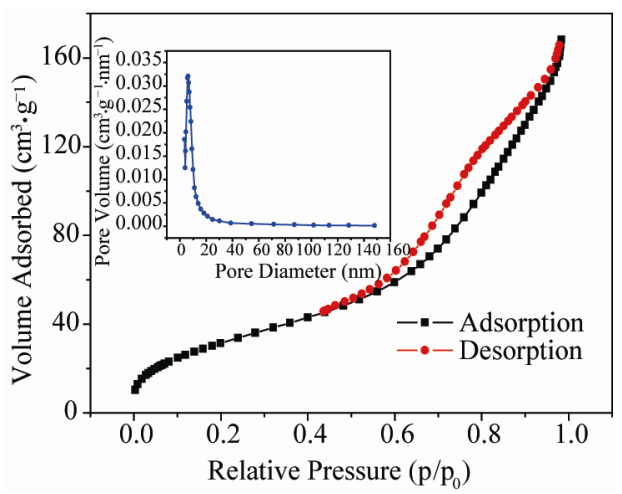

Figure 3. $\mathrm{N}_{2}$ adsorption-desorption isotherm and $\mathrm{BJH}$ poresize distribution of the as-prepared Mn-Co oxide.

Table 1. Textural properties of the as-prepared Mn-Co oxide from $\mathrm{N}_{2}$ adsorption-desorption measurements.

\begin{tabular}{ccc}
\hline BET surface $\left(\mathrm{m}^{2} \cdot \mathrm{g}^{-1}\right)$ & Pore volume $\left(\mathrm{cm}^{3} \cdot \mathrm{g}^{-1}\right)$ & Average pore size $(\mathrm{nm})$ \\
\hline 120 & 0.26 & 19 \\
\hline
\end{tabular}




\subsection{Cyclic Voltammograms}

Cyclic voltammetry is considered to be a powerful tool to indicate the capacitive behavior of electrode materials. Figure 4 shows the cyclic voltammograms of the Mn-Co oxide electrode measured in a scan rate range from 2 to $50 \mathrm{mV} \cdot \mathrm{s}^{-1}$ between -0.4 and $0.4 \mathrm{~V}$ vs. SCE in $6 \mathrm{~mol} \cdot \mathrm{L}^{-1}$ $\mathrm{KOH}$ aqueous electrolyte. Though slightly distorted at higher scan rates, all the cyclic voltammograms obtained are roughly rectangular in shape, and approximately symmetrical in anodic and cathodic directions, suggesting good capacitive behavior of the Mn-Co oxide electrode. The cyclic voltammograms exhibit a couple of approximately symmetric current peaks, i.e. an oxidation one around $0.16 \mathrm{~V}$ and a reduction one around $0.09 \mathrm{~V}$, which are due to intercalation/detercalation of protons or alkaline metal cations in the Mn-Co oxide electrode in $\mathrm{KOH}$ aqueous electrolyte, indicating a remarkable faradic pseudocapacitance contribution [31]. The small potential difference between the anodic peak and the cathodic peak suggests the high reversibility of the Mn-Co oxide electrode.

Specific capacitance of the Mn-Co oxide electrode can be calculated from the cyclic voltammograms according to the formula

$$
C_{S}=\frac{I}{m v}
$$

where $C_{s}$ is the specific capacitance $\left(\mathrm{F} \cdot \mathrm{g}^{-1}\right), m$ the mass (g) of the electroactive material, $v$ the potential scan rate $\left(\mathrm{V} \cdot \mathrm{s}^{-1}\right)$, and $I$ the even current response (A) defined by

$$
I=\frac{1}{2\left(V_{c}-V_{a}\right)} \int i \mathrm{~d} V
$$

( $V_{a}$ and $V_{c}$ represent the lowest and highest potentials $(\mathrm{V})$, respectively). Specific capacitance and specific current of the Mn-Co oxide electrode at ovarious scan rates were calculated from the cyclic voltammograms, as given in Figure 5. Figure 5(a) shows that specific capacitance decreases with increasing scan rate. The maximum spe-

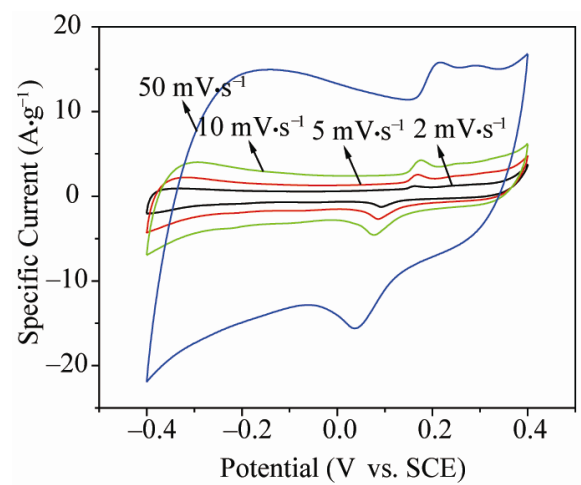

Figure 4. Cyclic voltammograms with various scan rates of the Mn-Co oxide electrode. cific capacitance of $383 \mathrm{~F} \cdot \mathrm{g}^{-1}$ is obtained for the $\mathrm{Mn}-\mathrm{Co}$ oxide electrode at a scan rate of $2 \mathrm{mV} \cdot \mathrm{s}^{-1}$. Importantly, a considerable specific capacitance of $225 \mathrm{~F} \cdot \mathrm{g}^{-1}$ is delivered even at a high scan rate of $50 \mathrm{mV} \cdot \mathrm{s}^{-1}$, indicating high power density of the Mn-Co oxide electrode. Figure 5(b) demonstrates that the specific current increases approximately linearly with increasing scan rates, confirming a high power characteristic of the Mn-Co oxide electrode material. Compared with the pristine manganese oxide consisting of $\alpha$ - and $\gamma-\mathrm{MnO}_{2}$ phases derived from manganese oxalate in our previous work [32], the capacitive performance of the prepared Mn-Co oxide is much improved in the SC and power property. Notably, the specific capacitance of the obtained Mn-Co oxide electrode material is larger than that of the pristine manganese oxide electrode materials derived from sol-gel route [12], coprecipitation [33] and improved reduction reaction [34]. Moreover, the facility of the solid-state coordination reaction we adopted has the advantages of a relatively low number of processing steps, low process costs and a great convenience of obtaining mixed oxides with desired chemical compositions [35]. From a commercial and economical point of view, it is a promising method for preparation of oxide electrode materials, especially, of multi-component mixed oxide electrode materials.

\subsection{Galvanostatic Charge-Discharge Analysis}

A symmetrical capacitor was assembled using a couple of the identical Mn-Co oxide electrodes separated by a porous polypropylene separator. Figure 6 shows the galvanostatic charge/discharge profiles of the Mn-Co oxide capacitor at different current densities. It can be seen that the charge/discharge profiles are somewhat curved, suggesting a pseudocapacitive characteristic of the Mn-Co oxide material. This is in accordance with the cyclic voltammetry result in Figure 4, where a couple of redox current peaks can be observed. The efficiency of the charge/discharge cycling is in the range of $0.88-0.92$.

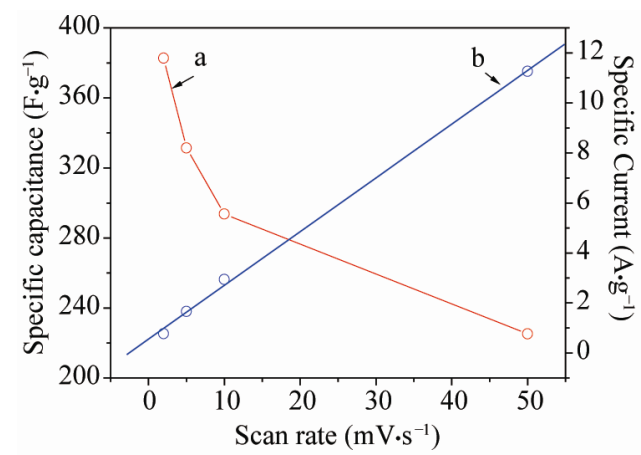

Figure 5. Scan rate dependence of (a) specific capacitance and (b) specific current of the obtained Mn-Co oxide electrode. 


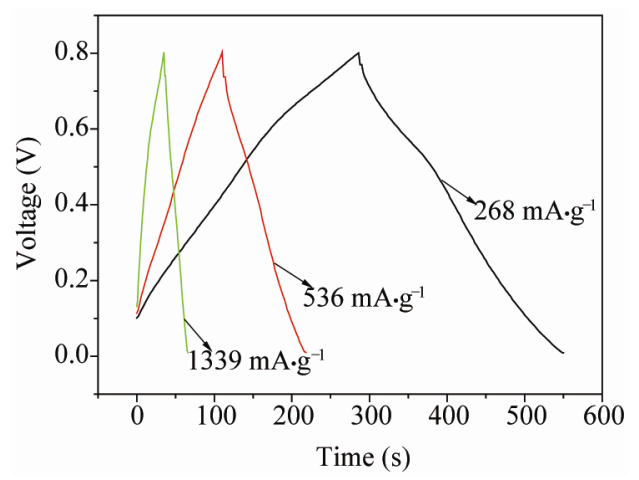

Figure 6. Galvanostatic charge/discharge profiles of the symmetrical Mn-Co oxide capacitor at various current densities.

The specific capacitance of the symmetrical Mn-Co oxide capacitor, expressed as the one of a single electrode, can be calculated by the formula, where $C_{s}$ is

$$
C_{S}=\frac{4 I \Delta t}{m \Delta V}
$$

the discharge specific capacitance (in $\mathrm{F} \cdot \mathrm{g}^{-1}$ ), $I$ the discharge current (in A), $\Delta t$ the discharge time (in s), $m$ the total mass (in g) of the electroactive material contained in the symmetrical capacitor, $\Delta V$ the discharge potential range (in V) [36]. The specific capacitance of the symmetrical Mn-Co oxide capacitor at current densities of $0.27,0.54$ and $1.34 \mathrm{~A} \cdot \mathrm{g}^{-1}$ was calculated to be 354,289 and $208 \mathrm{~F} \cdot \mathrm{g}^{-1}$, respectively. Apparently, the specific capacitance reduction is relatively small when increasing current density from 0.27 to $1.34 \mathrm{~A} \cdot \mathrm{g}^{-1}$, and a considerable specific capacitance of $208 \mathrm{~F} \cdot \mathrm{g}^{-1}$ is still retained at a high current density of $1.34 \mathrm{~A} \cdot \mathrm{g}^{-1}$, demonstrating a high power characteristic of the obtained Mn-Co oxide material. This is in agreement with the cyclic voltammetry result in Figure 5(b), where the specific current rises almost linearly with increasing scan rates.

For examination of the long-term cycling stability of the obtained Mn-Co oxide electrode material, the symmetrical Mn-Co oxide capacitor was subjected to charge/ discharge cycling at a current density of $1.34 \mathrm{~A} \cdot \mathrm{g}^{-1}$ for consecutive 500 cycles. The variation of the specific capacitance of the capacitor with cycle number is shown in Figure 7. During the first 100 cycles, the specific capacitance of the capacitor fades fast, decreasing by $\sim 12 \%$ of its initial specific capacitance. During the next 400 cycles, the specific capacitance fades slightly and becomes stable, decreasing by $\sim 3 \%$ of its initial specific capacitance. A considerable specific capacitance of 179 $\mathrm{F} \cdot \mathrm{g}^{-1}$, about $\sim 85 \%$ of its initial specific capacitance, is still remained for the capacitor after 500 cycles, suggestive of good cycling stability, which is of practical importance.

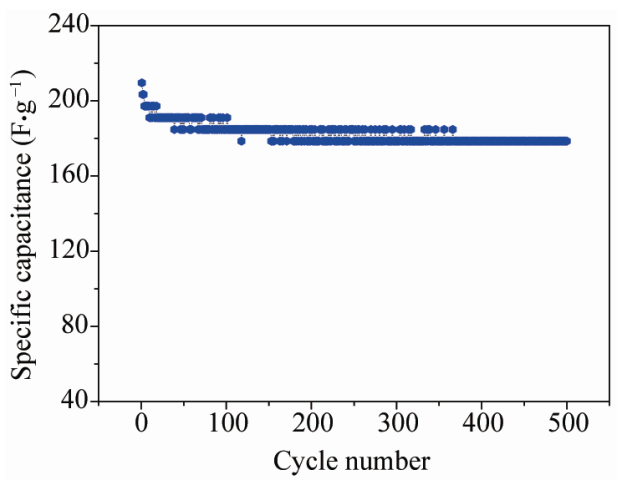

Figure 7. Cycling life of the symmetrical Mn-Co oxide capacitor at a current density of $1.34 \mathrm{~A} \cdot \mathrm{g}^{-1}$ between 0 and 0.8 V.

\section{Conclusion}

After the text edit has been completed, the paper is ready for the template. Duplicate the template file by using the Save As command, and use the naming convention prescribed by your journal for the name of your paper. In this newly created file, highlight all of the contents and import your prepared text file. You are now ready to style your paper. A mesoporous Mn-Co oxide powder with a particle size less than $100 \mathrm{~nm}$ was obtained by calcining the solid-state coordination reaction derived mixed oxalate $\mathrm{Mn}_{0.8} \mathrm{Co}_{0.2} \mathrm{C}_{2} \mathrm{O}_{4} \cdot \mathrm{nH}_{2} \mathrm{O}$ in air at $250^{\circ} \mathrm{C}$. The obtained $\mathrm{Mn}$-Co oxide was poorly crystallized with a tetragonal spinel structure. The Mn-Co oxide electrode possesses the maximum capacitance of $383 \mathrm{~F} \cdot \mathrm{g}^{-1}$ at a scan rate of $2 \mathrm{mV} \cdot \mathrm{s}^{-1}$, still retaining a considerable specific capacitance of $225 \mathrm{~F} \cdot \mathrm{g}^{-1}$ at a high scan rate of 50 $\mathrm{mV} \cdot \mathrm{s}^{-1}$. The specific current of the cyclic voltammograms varies roughly linearly with scan rates in the range of $2 \mathrm{mV} \cdot \mathrm{s}^{-1}$ to $50 \mathrm{mV} \cdot \mathrm{s}^{-1}$, demonstrating a high power characteristic of the obtained Mn-Co oxide electrode. At a charge/discharge current density of $1.34 \mathrm{~A} \cdot \mathrm{g}^{-1}$, the symmetrical Mn-Co oxide capacitor exhibits a specific capacitance of $210 \mathrm{~F} \cdot \mathrm{g}^{-1}$ during the first cycle, remaining $\sim 85 \%$ of its initial capacitance after 500 cycles. In comparison with powder-based pristine manganese oxide material, the Mn-Co oxide material we prepared shows better supercapacitive performance, which is a promising candidate for superacpacitor materials.

\section{Acknowledgements}

This work is financially supported by the Natural Science Foundation of Education Commission of Anhui Province under Grant no. KJ2012A045.

\section{REFERENCES}

[1] B. E. Conway, "Electrochemical Supercapacitors," Kluwer Academic Publishers, New York, 1999. 
[2] A. Burke, "Ultracapacitors: Why, How, and Where Is the Technology," Journal of Power Sources, Vol. 91, No. 1, 2000, pp. 37-50. doi:10.1016/S0378-7753(00)00485-7

[3] J. R. Miller and A. Burke, "Electrochemical Capacitors: Challenges and Opportunities for Real-World Applications," Electrochemical Society Interface, Vol. 17, No. 1, 2008, pp. 53-57.

[4] Y. Liu, K. X. Li, J. L. Wang, G. H. Sun and C. G. Sun, "Preparation of Spherical Activated Carbon with Hierarchical Porous Texture," Journal of Materials Science, Vol. 44, No. 17, 2009, pp. 4750-4753. doi:10.1007/s10853-009-3710-6

[5] A. G. Pandolfo and A. F. Hollenkamp, "Carbon Propertites and Their Role in Supercapacitors," Journal of Power Sources, Vol. 157, No. 1, 2006, pp. 11-27. doi:10.1016/j.jpowsour.2006.02.065

[6] T. Nathan, A. Aziz, A. F. Noor and S. R. S. Prabaharan, "Nanostructured $\mathrm{NiO}$ for Electrochemical Capacitors: Synthiesis and Electrochemical Properties," Journal of Solid State Electrochemistry, Vol. 12, No. 7-8, 2007, pp. 1003-1009. doi:10.1007/s10008-007-0465-3

[7] J. Cheng, G. P. Cao and Y. S. Yang, "Characterization of Sol-Gel-Derived $\mathrm{NiO}_{\mathrm{x}}$ Xerogels Supercapacitors," Journal of Power Sources, Vol. 159, No. 1, 2006, pp. 734-731. doi:10.1016/j.jpowsour.2005.07.095

[8] D. Bélanger, T. Brousse and J. W. Long, "Manganese Oxides: Battery Materials Make the Leap to Electrochemical Capacitors," Electrochemical Society Interface, Vol. 17, No. 1, 2008, pp. 47-52.

[9] D. K. Bhat and M. S. Kumar, "N and P Doped Poly(3,4Ethylenedioxythiophene) Electrode Materials for Symmetric Redox Supercapacitors," Journal of Materials Science, Vol. 42, No. 19, 2008, pp. 8158-8162 doi:10.1007/s10853-007-1704-9

[10] H. Guan, L. Z. Fan, H. C. Zhang and X. H. Qu, "Polyaniline Nanofiber Obtained by Interfacial Polymerization for High-Rate Supercapacitors," Electrochimica Acta, Vol. 56, No. 2, 2010, pp. 964-968. doi:10.1016/j.electacta.2010.09.078

[11] E. H. Liu, R. Ding, X. Y. Meng, S. T. Tan and J. C. Zhou, "Potentiodynamical Deposition of Nanosized Manganese Oxides as High Capacitance Electrochemical Capacitors," Journal of Materials Science Materials in Electronics, Vol. 18, No. 12, 2007, pp. 1179-1182 doi:10.1007/s10854-007-9369-3

[12] R. N. Reddy and R. G. Reddy, "Synthesis and Electrochemical Characterization of Amorphous $\mathrm{MnO}_{2}$ Electrochemical Capacitor Electrode Material," Journal of Power Sources, Vol. 132, No. 1-2, 2004, pp. 315-320 doi:10.1016/j.jpowsour.2003.12.054

[13] T. Brousse, M. Toupin, R. Dugas, L. Athouël, O. Crosnier and D. Bélange, "Crystalline $\mathrm{MnO}_{2}$ as Possible Alternatives to Amorphous Compounds in Electrochemical Supercapacitors," Journal of the Electrochemical Society, Vol. 153, No. 12, 2006, pp. A2171-A2180. doi:10.1149/1.2352197

[14] L. Athouel, F. Moser, R. Dugas, O. Crosnier, D. Bélanger and T. Brousse, "Variation of the $\mathrm{MnO}_{2}$ Birnessite Structure upon Charge/Discharge in an Electrochemical Su- percapacitor Electrode in Aqueous $\mathrm{Na}_{2} \mathrm{SO}_{4}$ Electrolyte," Journal of Physical Chemistry, Vol. 112, No. 18, 2008, pp. 7270-7277. doi:10.1021/jp0773029

[15] F. B. Zhang, Y. K. Zhou and H. L. Li, "Nanocrystalline $\mathrm{NiO}$ as an Electrode Material for Electrochemical Capacitor," Materials Chemistry and Physics, Vol. 83, No. 2-3, 2004, pp. 260-264. doi:10.1016/i.matchemphys.2003.09.046

[16] X. M. Liu, X. G. Zhang and S. Y. Fu, "Preparation of Urchinlike NiO Nanostructures and Their Electrochemical Capacitive Behaviors," Materials Research Bulletin, Vol. 41, No. 3, 2006, pp. 620-627. doi:10.1016/j.materresbull.2005.09.006

[17] T. Y. Wei, C. H. Chen, K. H. Chang, S. Y. Lu and C. C. $\mathrm{Hu}$, "Cobalt Oxide Aerogels of Ideal Supercapacitive Properties Prepared with an Epoxide Synthetic Route," Chemistry of Materials, Vol. 21, No. 14, 2009, pp. 3228-3233. doi:10.1021/cm9007365

[18] Y. Y. Gao, S. L. Chen, D. X. Cao, G. L. Wang and J. L. Yin, "Electrochemical Capacitance of $\mathrm{Co}_{3} \mathrm{O}_{4}$ Nanowire Arrays Supported on Nickel Foam," Journal of Power Sources, Vol. 195, No. 6, 2010, pp. 1757-1760. doi:10.1016/j.jpowsour.2009.09.048

[19] E. H. Liu, W. Li, J. Li, X. Y. Meng and S. T. Tan, "Preparation and Characterization of Nanostructured $\mathrm{NiO} / \mathrm{MnO}_{2}$ Composite Electrode for Electrochemical Supercapacitors," Materials Research Bulletin, Vol. 44, No. 5, 2009, pp. 1122-1126. doi:10.1016/j.materresbull.2008.10.003

[20] H. Kim and B. N. Popov, "Synthesis and Characterization of $\mathrm{MnO}_{2}$ Based Mixed Oxides as Supercapacitors," Journal of The Electrochemical Society, Vol. 150, No. 3, 2003, pp. D56-D62. doi:10.1149/1.1541675

[21] J. P. Zheng, "Ruthenium Oxide-Carbon Composite Electrodes for Electrochemical Capacitors," Electrochemical and Solid-State Letters, Vol. 2, No. 8, 1999, pp. 359-361 doi:10.1149/1.1390837

[22] M. Nakayama, A. Tanaka, Y. Sato, T. Tonosaki and K. Ogura, "Electrodeposition of Manganese and Molybdenum Mixed Oxide Thin Films and Their Charge Storage Properties," Langmuir, Vol. 21, No. 13, 2005, pp. 5907 5913. doi:10.1021/la050114u

[23] X. Y. Xie, W. W. Liu, L. Y. Zhao and C. D. Huang, "Structural and Electrochemical Behavior of Mn-V Oxide Synthesized by a Novel Precipitation Method," Journal of Solid State Electrochemistry, Vol. 14, No. 1, 2010, pp. 1585-1594. doi:10.1007/s10008-009-0987-y

[24] P. Y. Chuang and C. C. Hu, "The Electrochemical Characteristics of Binary Manganese-Cobalt Oxides Prepared by Anodic Deposition," Materials Chemistry and Physics, Vol. 92, No. 1, 2005, pp. 138-145. doi:10.1016/j.matchemphys.2005.01.004

[25] G. Y. Zhao, C. L. Xu and H. L. Li, "Highly Ordered Cobalt-Manganese Oxide (CMO) Nanowire Array Thin Film on $\mathrm{Ti} / \mathrm{Si}$ Substrate as an Electrode for Electrochemical Capacitor," Journal of Power Sources, Vol. 163, No. 2, 2007, pp. 1132-1136. doi:10.1016/j.jpowsour.2006.09.085

[26] E. Machefauxa, T. Brousseb, D. Bélangerc and D. Guyomard, "Supercapacitor Behavior of New Substituted Man- 
ganese Dioxides," Journal of Power Sources, Vol. 165, No. 2, 2007, pp. 651-655

doi:10.1016/j.jpowsour.2006.10.060

[27] D. L. Fang, Z. B. Wang, P. H. Yang, W. Liu and C. S. Chen, "Preparation of Ultra-Fine Nickel Manganite Powders and Ceramics by a Solid-State Coordination Reaction," Journal of the American Ceramic Society, Vol. 89, No. 1,2006 , pp. 230-235. doi:10.1111/j.1551-2916.2005.00666.x

[28] D. L Fang, C. S Chena and A. J. A. Winnubstc, "Preparation and Electrical Properties of $\mathrm{Fe}_{\mathrm{x}} \mathrm{Cu}_{0.10} \mathrm{Ni}_{0.66} \mathrm{Mn}_{2.24-\mathrm{x}} \mathrm{O}_{4}$ $(0 \leq \mathrm{x} \leq 0.90)$ NTC Ceramics," Journal of Alloys and Compounds, Vol. 454, No. 1-2, 2008, pp. 286-291. doi:10.1016/j.jallcom.2006.12.059

[29] F. Rouquerol, J. Rouquerol and K. Sing, "Adsorption by Powers and Porous Solids: Principles Methodology and Applications," Academic Press, San Diego, 1999.

[30] T. Sreethawong, S. Chavadej, S. Ngamsinlapasathian and S. Yoshikawa, "A Modified Sol-Gel Process-Derived Highly Nanocrystalline Mesoporous NiO with Narrow Pore Size Distribution," Colloids and Surfaces A: Physicochemical and Engineering Aspects, Vol. 296, No. 1-3, 2007, pp. 222-229. doi:10.1016/j.colsurfa.2006.09.048

[31] E. Raymundo-Pinero, V. Khomenko and E. Frackowiak, "Performance of Manganese Oxide/CNTs Composites as Electrode Materials for Electrochemical Capacitors," Journal of The Electrochemical Society, Vol. 152, No. 1, 2005, pp. 229-235. doi:10.1149/1.1834913

[32] D. L. Fang, B. C. Wu, A. Q. Mao, Y. Yan and C. H. Zheng, "Supercapacitive Properties of Ultra-Fine $\mathrm{MnO}_{2}$ Prepared by a Solid-State Coordination Reaction," Journal of Alloys and Compounds, Vol. 507, No. 2, 2010, pp. 526-530. doi:10.1016/j.jallcom.2010.08.010

[33] M. Toupin, T. Brousse and D. Bélanger, "The Influence of Microstructure on the Charge Storage Properties of Chemically Synthesized Manganese Dioxide," Chemistry of Materials, Vol. 14, No. 9, 2002, pp. 3946-3952. doi:10.1021/cm020408q

[34] S. J. Bao, B. L. He, Y. Y. Liang, W. J. Zhou and H. L. Li, "Synthesis and Electrochemical Characterization of Amorphous $\mathrm{MnO}_{2}$ for Electrochemical Capacitor," Materials Science and Engineering: A, Vol. 397, No. 1-2, 2005, pp. 305-309. doi:10.1016/j.msea.2005.02.058

[35] C. H. Zheng and D. L. Fang, "Preparation of Ultra-Fine Cobalt-Nickel Manganite Powders and Ceramics Derived From Mixed Oxalate," Materials Research Bulletin, Vol. 43, No. 7, 2008, pp. 1877-1882. doi:10.1016/j.materresbull.2007.06.061

[36] J. Li, X. Y. Wang, Q. H. Huang, S. Gamboa and P. J. Sebastian, "A New Type of $\mathrm{MnO}_{2} \cdot \mathrm{xH}_{2} \mathrm{O} / \mathrm{CRF}$ Composite Electrode for Supercapacitors," Journal of Power Sources, Vol. 160, No. 2, 2006, pp. 1501-1505. doi:10.1016/j.jpowsour.2006.02.045 